\title{
Evaluation of Breeding Programs Susceptibility for Two Important Forage Crops Using DNA Barcoding
}

\author{
Abdel Aziz.T. Bondok ${ }^{1}$
}

\begin{abstract}
This investigation was carried out to identify and evaluate Medicago sativa and Trifolium alexandrinum probability for breeding program based on two bar-coding genes (rbcl and Cox1 genes). Identification of Medicago sativa Baladi 1 was performed through rbcl and Cox1 genes. Medicago sativa Baladi 1 was identified as Medicago sativa voucher G00199095 ribulose-1,5-bisphosphate carboxylase/oxygenase large subunit (rbcL) gene, partial cds; chloroplast (Sequence ID: KJ204375.1) and Medicago sativa voucher Ahrendsen_23 for rbcl and Cox1 genes respectively.
\end{abstract}

Identity values were recorded with $90 \%$ of identity for alfalfa, Baladi 1 Genotype ribulose - 1/5 - bisphosphate carboxylase / oxygenase large subunit (rbcl) gene (sequences ID: KJ206375.1) also, identity values were recorded with $91.24 \%$ of identity for alfalfa Baladi 1 Genotype, cytochrome c oxiddase bubunit I gene (cox 1) (sequence ID: KJ 204375.1).

Trifolium alexandrinum Helaly genotype was identified as Trifolium alexandrinum (Sequence ID: HM850407.1) and Trifolium alexandrinum voucher K-016Hv (Sequence ID: KU234213.1) as rbcl and Cox1 genes respectively. Affiliation of genetic origin was detected for Trifolium alexandrinum with $100 \%$ of similarity with origin source which indicate highly possibility for applying breeding programs comparing with Medicago sativa which reflect the lowest genetic similarity with origin source.

Key Words: DNA Barcoding; rbcL; Cox 1; Trifolium alexandrinum; Medicago sativa; NCBI BLAST.

\section{INTRODUCTION}

DNA sequences to identify organisms have been proposed as a more ancient approach than traditional taxonomic practices (Blaxter, 2004; Tautz et al., 2003). Kress et al. (2005) have demonstrated the effectiveness of such DNA bar-coding in angiosperms using nrDNA and non-coding cpDNA sequences. In Trifolium, extensive germplasm collections of most wild-collected species exist (Morris and Greene, 2001).

Trifolium is a member of the large clad of legumes lacking one copy of the chloroplast inverted repeat, the IRLC (Lavin et al., 1990; Liston, 1995). Molecular phyllogenetic studies have identied a strongly supported "vicioid clad" within the IRLC composed of the tribes Trifolieae and Fabeae
Molecular polymorphism with random amplified polymorphic DNA (RAPD) and inter simple sequence repeat (ISSR) were employed to determine taxonomic relationships among 25 samples representing nine species of Orobanche L. (Orobanchaceae) dendrogram produced by the analysis of the molecular data (RAPD and ISSR) resembled that constructed by NJ dendrogram for the morphological variation Sahrawy and Karakishi (2015) evaluated the use of two chloroplast regions, trnL and $\mathrm{rpoC} 1$, and a nuclear internal transcriber region, ITS2, for their efficiency to barcode the main Mediterranean leguminous crops. Twenty-five legume species were studied. Species identification based on the sequence similarity approach was performed using the GenBank database. The DNA regions trnL and ITS2 successfully (100\%) discriminated the Mediterranean crop legume species used, while rpoC1 identified only $72 \%$ of them. Furthermore, the use of the trnL region enabled the discrimination of even very closely related species, like Phaseolus lunatus and P. coccineus or Vicia faba subsp major with V. faba subsp minor, which are so closely related that even in NCBI they were both referred as Phaseolus vulgaris and V. faba, respectively. trnL and ITS2 are efficient DNA bar-coding target regions in order to discriminate Mediterranean leguminous crops and provide a reliable and efficient tool for the scientific, agricultural and industrial community. (Madesis et al., 2012).

Badr (2001) examined Trifolium alexandrinum using AFLP data. The data support a close relationship of T. alexandrinum accessions from Syria and Egypt to T. apertum, T. berytheum, and T. salmoneum ability of these species to cross freely indicates that $T$. salmoneum and $T$. berytheum may be regarded as the primary ancestors from, which man domesticated Egyptian clover through artificial selection in Syria. Following domestication, the earlier forms of the crop species could have been taken into rain-fed cultivation in Palestine and irrigated cultivation in Egypt. In this regard, the domestication of Egyptian clover may be analogous to other crops, such as barley and wheat, which were also domesticated in the Fertile Crescent and taken into cultivation in the Nile Valley. It appears that genetic improvement of the crop occurred in Egypt

${ }^{1}$ Forage Crops Research Dept. Field Crops Res. Institute, Agriculture Research Center. Giza,Egypt. Received March 2, 2017, Accepted March 15, 2017 
after cultivation, and that the varieties that were developed in Egypt were later distributed worldwide.

Parsimony and Bayesian phyllogenetic analyses were conducted based on nuclear ribosomal DNA internal transcribed spacer and chloroplast trnL intron sequences obtained from 218 of the ca. 255 species of Trifolium, representatives from 11 genera. Incongruence between the nrDNA and cpDNA results suggests six cases of apparent hybrid speciation, and identifies the putative progenitors of the allopolyploids $T$. dubium, a widespread weed, and $T$. repens, the most commonly cultivated clover species (Ellison et al., 2006).

Origin and ancestry of Egyptian clover ( Trifolium alexandrinum L.) As revealed by AFLP markers. The origin and ancestry for Egyptian clover, Trifolium alexandrinum, was examined using AFLP data. The data support a close relationship of $\mathrm{T}$. alexandrinum accessions from Syria and Egypt to $\mathrm{T}$. apertum, $\mathrm{T}$. berytheum, and T. salmoneum. However, cross ability and geographic distributions suggest that $\mathrm{T}$. apertum is an unlikely progenitor. In contrast, $T$. salmoneum appears to be the most probable progenitor for Syrian material of Egyptian clover, although a close relationship to $\mathrm{T}$. berytheum was also revealed. The ability of these species to cross freely indicates that $T$. salmoneum and T. berytheum may be regarded as the primary ancestors from, which man domesticated Egyptian clover through artificial selection in Syria. Following domestication, the earlier forms of the crop species could have been taken into rain-fed cultivation in Palestine and irrigated cultivation in Egypt. In this regard, the domestication of Egyptian clover may be analogous to other crops, such as barley and wheat, which were also domesticated in the Fertile Crescent and taken into cultivation in the Nile Valley. It appears that genetic improvement of the crop occurred in Egypt after cultivation, and that the varieties that were developed in Egypt were later distributed worldwide. Kergoat et al., (2004) reconstructed partial sequences of three mitochondrial genes (12S rRNA, cytochrome b, and cytochrome c oxidase subunit I) phylogeny of European seed beetles (Bruchidae) belonging to the genera Bruchus Linnaeus and Bruchidius Schilsky. Adult beetles examined in this study were obtained from larvae bred from seeds directly collected in the field. Parsimony, maximum likelihood, and Bayesian inference were used to infer phylogenetic relationships among species. Both genera, Bruchidius and Bruchus, formed monophyletic groups in all analyses.

Sequence of the chloroplast-genome encoded rbcL gene from Medicago sativa cv. Regen $\mathrm{S}$ was compared to pea. Alfalfa shares $94.1 \%$ nucleotide sequence homology with pea for 1721 bases spanning the gene beginning 213 bases upstream of the coding sequences through 83 bases into the $3^{\prime}$ flanking region ending at position 1508 . Pea sequences are highly divergent from alfalfa after this point. The deduced amino acid sequence is $94.3 \%$ homologous to that of pea, with $56 \%$ $(15 / 27)$ of the substitutions non-conservative (Aldrich et al., 1987). Also, DNA barcodes from most herbal products $(91 \%)$ were recovered and all leaf samples $(100 \%)$, with $95 \%$ species resolution using a tiered approach $(r b c L+I T S 2)$. Most $(59 \%)$ of the products tested contained DNA barcodes from plant species not listed on the labels. Although we were able to authenticate almost half $(48 \%)$ of the products, onethird of these also contained contaminants and or fillers not listed on the label. Product substitution occurred in $30 / 44$ of the products tested and only $2 / 12$ companies had products without any substitution, contamination or fillers. Some of the contaminants we found pose serious health risks to consumers (Newmaster et al., 2013).

The aime of the present study was to:

- Use DNA Barcoding to Identify Medicago Sativa Baladi 1 and Trifolum Alexandrinum Helaly Genotypes.

Evaluation of Breeding programs susceptibility for Medicago Sativa Baladi 1 and Trifolium alexandriunum, Helaly Genotypes using DNA Barcoding (rbcL and Cox 1) genes.

\section{MATERIALS AND METHODS}

The Seeds were obtained from the Forage Crops Research Department (ARC) (Medicago Sativa alfalfa, Baladi 1 and Trifolum alexandrium, Egyptian clover Helaly).

\section{METHODS:}

\section{Sequence Database for DNA Bar-coding:}

Identification and comparing sequences under study was carried out at National Center for Biotechnology Information (NCBI) database.

\section{Taxon sampling and origin of sequences.}

Two Leguminosae samples (Trifolium alexandrinum and Medicago sativa) were studied including in reference database.

\section{DNA extraction, amplification and sequencing.}

Freshly collected specimens were stored on silica prior to extraction. DNA was extracted using the Gene JET Genomic DNA purification kit (ThermoScientific) following the manufacturer's protocol. As shown in table (1), two plastid regions were amplified, ribulose-1,5-bisphosphate carboxylase/oxygenase large subunit (rbcL) gene and cytochrome c oxidase subunit 1 gene (Cox1) with specific primer according to Kergoat, et al., 2004 and Cai et al., 2008, Gurdon et al., 2014, 
Table 1. Specific Primer sequence under study

\begin{tabular}{|c|c|c|c|c|c|}
\hline \multicolumn{3}{|c|}{ Primer sequence } & Length & $\mathbf{T m}$ & GC\% \\
\hline \multirow{4}{*}{ Trifolium alexandrinum } & Rhcl & CAAGGCTTTGCGTGCTCTAC & \multirow{2}{*}{741} & 59.83 & 55.00 \\
\hline & KOCI & TATCGCGGCAATAGTGAGCC & & 60.32 & 55.00 \\
\hline & \multirow{2}{*}{ Cox 1} & ATATTGCCCATAGAGGCCCTTC & \multirow{2}{*}{289} & 59.69 & 50.00 \\
\hline & & GCATAGTGATTGCTCCTGCT & & 58.04 & 50.00 \\
\hline \multirow{4}{*}{ Medicago sativa } & \multirow{2}{*}{$\mathrm{Rbcl}$} & CGGCTACCGATGGACTTACC & \multirow{2}{*}{339} & 59.97 & 60.00 \\
\hline & & GTTCCACССТCTTCCAGACG & & 60.04 & 60.00 \\
\hline & & TATGGTTTGCCGGCGATGAT & \multirow{2}{*}{759} & 60.18 & 50.00 \\
\hline & Cox1 & TTGTAATTGCCCCTGCCAGT & & 59.89 & 50.00 \\
\hline
\end{tabular}

Young et al., (2011) for Medicago sativa and Trifolium alexandrinum. Amplified products were separated by gel electrophoresis (1.0\% Agarose). Obtained RT-PCR products were purified from Agarose gel and quantities spectrophotometrically preparing for sequencing experiment through ABI Prism 7000 instrument based on manufacturer procedure

Nucleotide sequence accession numbers.

Nucleotide sequences of bar-coding genes ( $\mathrm{rbcl}$ and Cox1 genes) were submitted to identified through NCBI BLAST program (http://www.ncbi.nlm.nin.gov/BLAST/) as a single sense-strand contiguous sequence for each of Baladi 1 and Helaly genotypes. PCR products were directly sequenced in 2 directions of each fragment with a Big Dye terminator v3.1 Cycle sequencing kit (PE Applied Biosystems, Foster City, CA, USA) in an automated ABI 3730 sequencer (PE Applied Biosystems). The

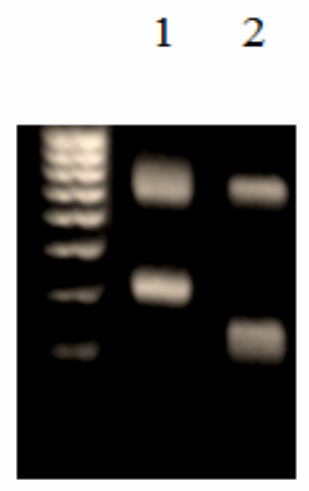

Photograph 1. Specific PCR products for 1. Medicago sativa Baladi 1 genotype and 2. Trifolium alexandrinum Helaly genotype with 339,759 bp and 741, 289 bp for $r b c l$ marker gene and cytochrome c oxidase subunit 1 gene respectively sequences were aligned using the CLUSTAL W program.

\section{RESULTS AND DISCUSSION}

\section{Specific gene detection technique:}

Main purpose of this investigation is identifying and evaluating Medicago sativa and Trifolium alexandrinum probability for breeding program. Thus, two bar-coding genes (rbcl and Cox1 genes) were employed for identification. Based on alignment data with reference genes, genetic similarity were evaluated and possibility for breeding program were evaluated for Medicago sativa and Trifolium alexandrinum.

Photograph (1 and 2) show molecular weight parameters. Thus, specific fragments lengths were detected for each of Medicago sativa and Trifolium alexandrinum.

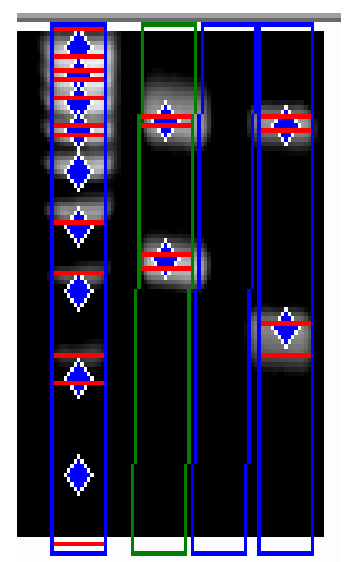

Photograph 2. Detection of specific PCR products for Medicago sativa Baladi 1 genotype and Trifolium alexandrinum Helaly with 339, 759 bp and 741, 289 bp for rbcl marker gene and cytochrome c oxidase subunit 1 gene respectively 


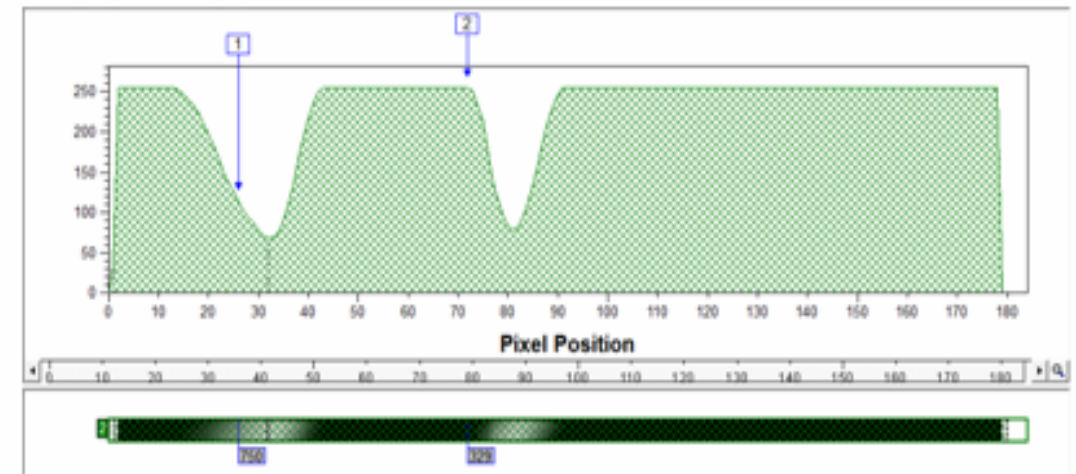

\begin{tabular}{|c|c|c|c|c|c|c|c|c|}
\hline Band No & Position & Volume & Peak Height & Aves & Band $\%$ & Lane \% & MW & क \\
\hline 1 & 26 & 192404.00 & 114.56 & 992.00 & 14.83 & 14.83 & 750.125 & 0.142 \\
\hline 2 & 72 & 1105307.00 & 254.72 & 4736.00 & 85.17 & 85.17 & 329.030 & 0.393 \\
\hline
\end{tabular}

Photograph 3. Specific PCR products for Medicago sativa Baladi 1 genotype with 339, 759 bp

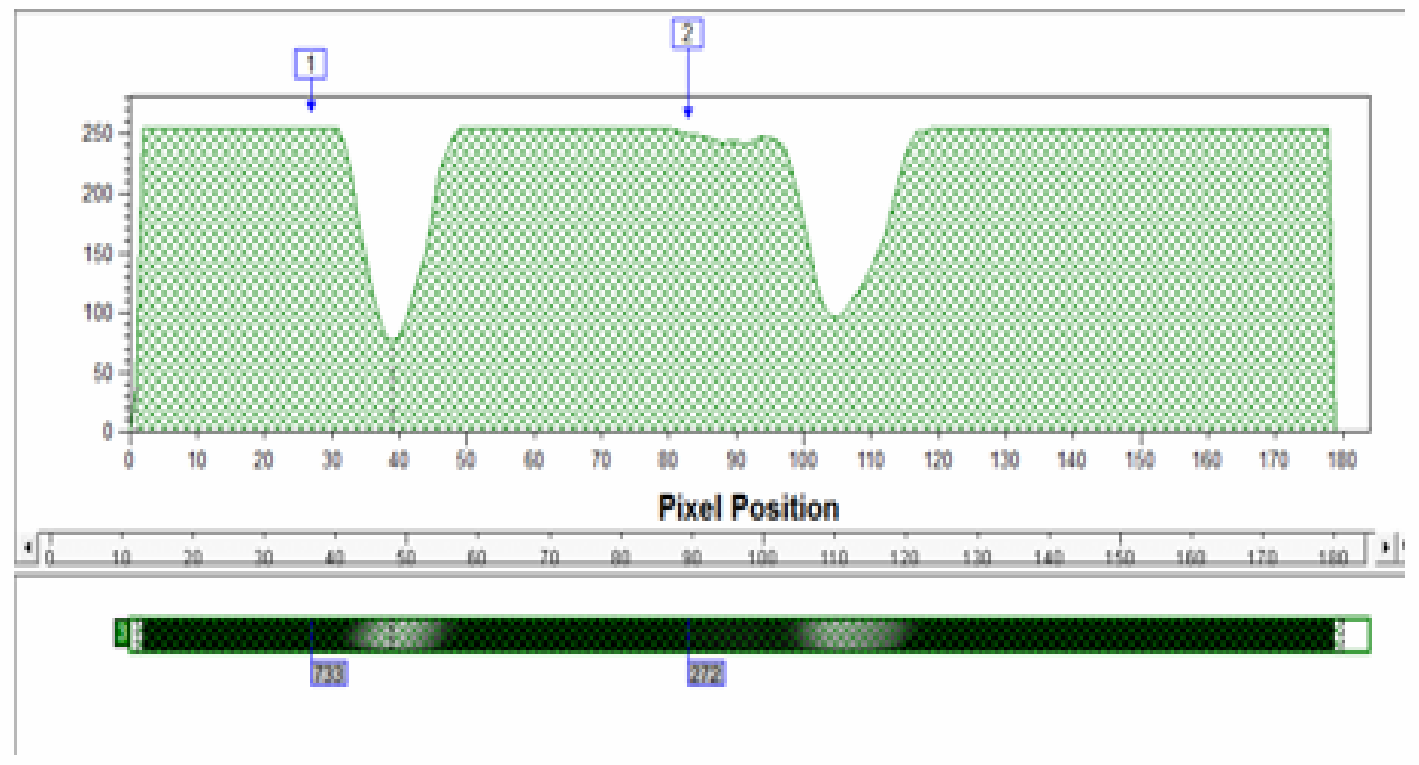

\begin{tabular}{|c|c|c|c|c|c|c|c|c|}
\hline Band lib & Poution & Volum & Peak Heyts & Aces & Band 5 & $\tan 8$ & MW & $\mathrm{PA}$ \\
\hline 1 & $\vec{x}$ & SSDO & 10.22 & 400 & 0.53 & 0.45 & 741.179 & 0.52 \\
\hline 2 & 6 & $100) 12700$ & วิต & 451200 & not & $M \omega$ & $2 a s+19$ & 030 \\
\hline
\end{tabular}

Photograph 4. Specific PCR products for Trifolium alexandrines Helaly with 741, 289 bp 
CLUSTAL 0(1.2.4) multiple sequence alignment

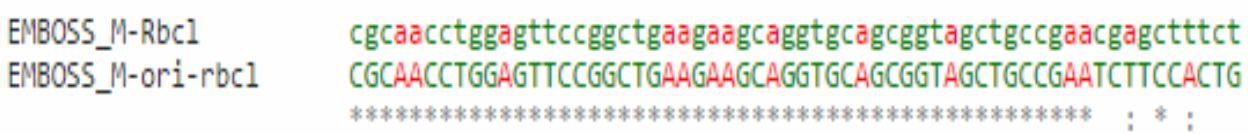

EMBOSS M-RbCl EMBOSS_M-ori-rbc1

EMBOSS_M-Rbcl EMBOSS_M-ori-rbc1

EMBOSS_M-Rbc1 EMBOSS M-ori-rbcl

EMBOSS_M-Rbc1 EMBOSS_M-ori-rbcl

EMBOSS_M-RbCI

EMBOSS_M-ori-rbc1 ggacatggacggcatcggctaccgatggacttaccagtcttgatcgttataaaggacgct GGACATGGACAACTGTGTGGACCGATGGACTTACCAGTCTTGATCGTTATAAAGGACGCT

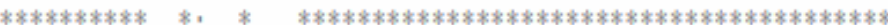

gctaccacatcgaacctgttgctggagaagagactcaatttattgcttatgtagcttatc GCTACCACATCGAACCTGTTGCTGGAGAAGAGACTCAATTTATTGCTTATGTAGCTTATC $* * * * * * * * * * * * * * * * * * * * * * * * * * * * * * * * * * * * * * * * * * * * * * * * * * * * * * * * * * * *$

ccttagacctttttgaagaaggttctgttactaacatgtttacctccattgtaggtaatg CCTTAGACCTTTTTGAAGAAGGTTCTGTTACTAACATGTTTACCTCCATTGTAGGTAATG $* * * * * * * * * * * * * * * * * * * * * * * * * * * * * * * * * * * * * * * * * * * * * * * * * * * * * * * * * * * *$

aacgctttctcaaggccttgcgtgctctacgtctggaagag-ggtggaaccccgttgctt TATTTGGGTTCAAGGCCTTGCGTGCTCTACGTCTGGAAGATTTGCGAATCCCCGTTGCTT $: * \quad * * * * * * * * * * * * * * * * * * * * * * * * * * * * * * \quad * * * * ; * * * * * * * * * *$

atgttaaaactttccaaggtgaggtctcttgaatccaagt

ATGTTAAAACTTTCCAAGGT

Figure 1. Comparison alignments between rbcl marker gene for Medicago sativa Baladi 1 genotype and rbcl reference sequence

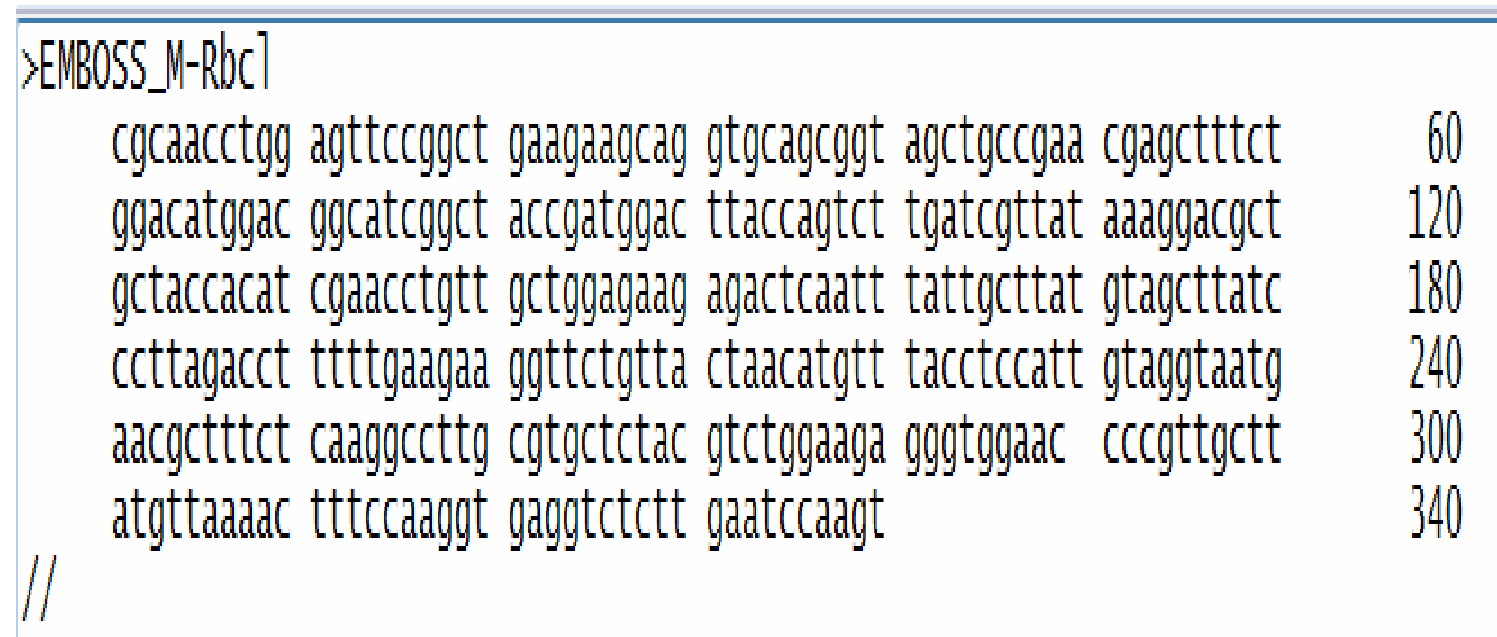

Figure 2. Rbcl marker gene sequence for Medicago sativa Baladi 1 genotype

(DNA Barcoding of alafalfa Baladi I Genotype (rbcL) gene) 


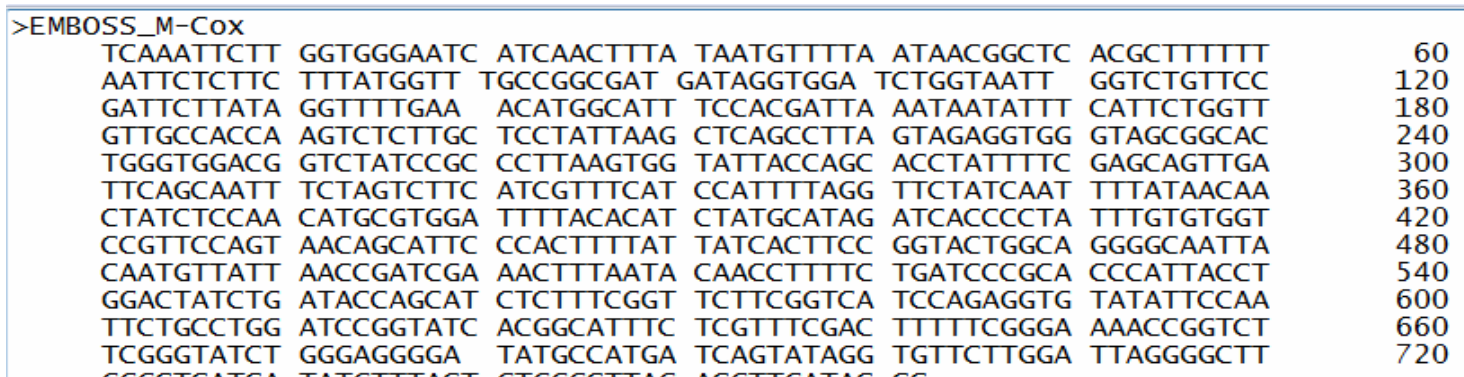

Figure 3. Cytochrome c oxidase subunit 1 gene (Cox1) marker gene sequence for Medicago sativa Baladi 1 genotype

\section{(DNA Barcoding of alfalfa Baladi 1 Genotype (Cox 1) gene)}

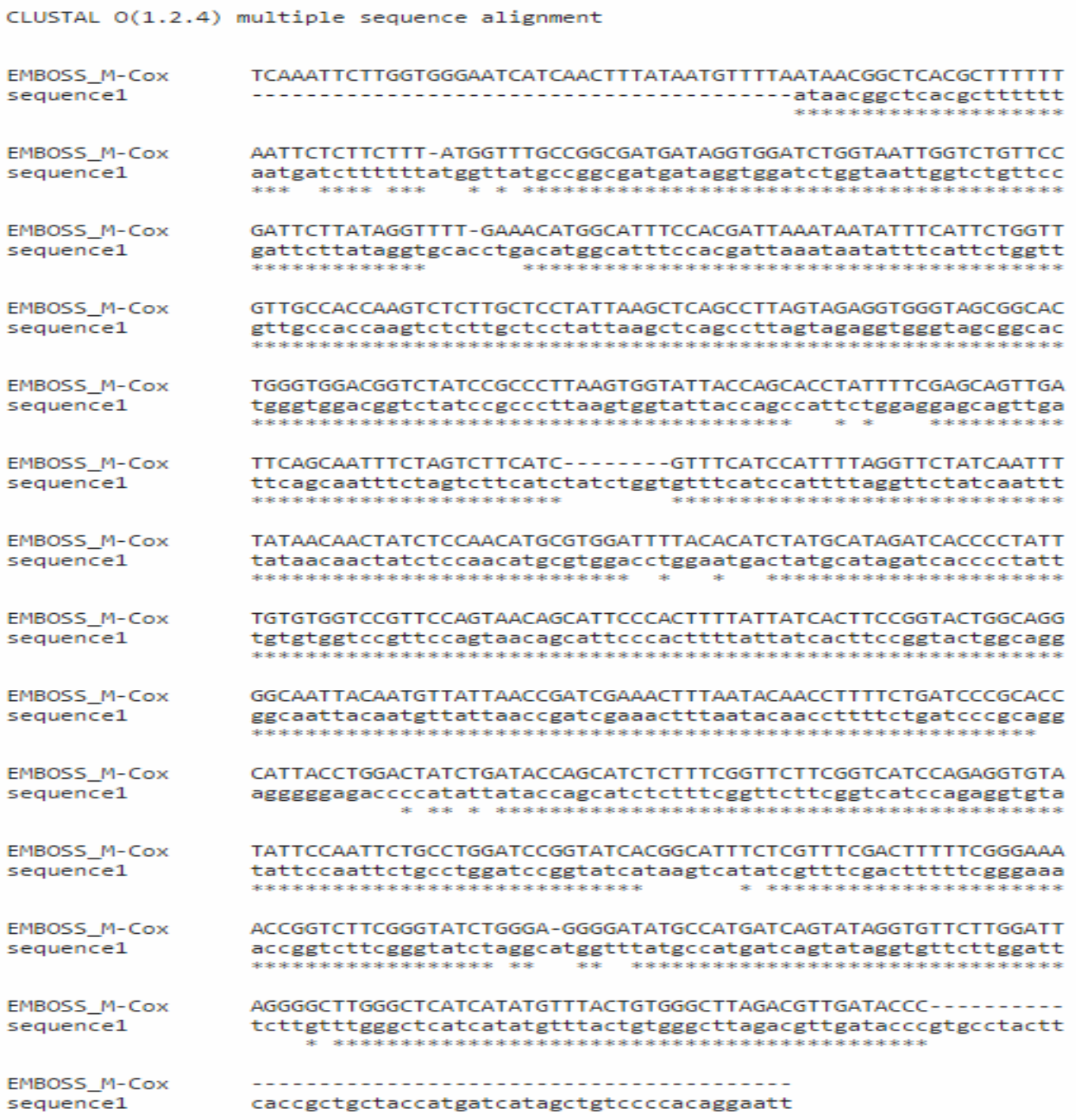

Figure 4. Comparison alignments between cytochrome c oxidase subunit 1 gene for Medicago sativa Baladi 1 genotype and rbcl reference sequence 
Identification of Medicago sativa Baladi 1 genotype was performed through rbcl and Cox 1 genes. Figure (1) shows comparing rbcl marker gene for Medicago indicated identification as Medicago sativa voucher G00199095 ribulose-1,5-bisphosphate carboxylase/oxygenase large subunit (rbcL) gene, partial cds; chloroplast (Sequence ID: KJ204375.1).

To evaluate genetic stability for Medicago sativa baladi1, rbcl marker gene for Medicago sativa and rbcl original sequence were compared. Interestingly, comparison data showed that, $90 \%$ of genetic similarity was detected between rbcl marker gene for Medicago sativa and rbcl reference sequence. (Fig. 2).

For further confirmation cytochrome c oxidase subunit 1 gene (Cox1) marker gene was applied for identification Medicago sativa Baladi 1 genotype (Fig.3) and indicated as Medicago sativa voucher Ahrendsen_23 cytochrome c oxidase subunit 1 gene, complete cds; mitochondrial.

Highly genetic similarity was founded between cytochrome c oxidase subunit 1 gene (Cox1) for Medicago sativa and c oxidase subunit 1 gene (Cox1) for reference sequence and estimated with $91.24 \%$ (Fig.4).

Suspected Trifolium alexandrinum Helaly genotype was identified based on ribulose-1,5-bisphosphate carboxylase/oxygenase large subunit (rbcL) gene, Trifolium sample was identified as Trifolium alexandrinum ribulose-1,5-bisphosphate carboxylase/oxygenase large subunit (rbcL) gene, partial cds; chloroplast (Sequence ID: HM850407.1) with $100 \%$ of genetic identity (fig.5).

To esstimate genetic relationship between Trifolium alexandrinum and genetic origin of Trifolium alexandrinum, alignment results were analyzed between ribulose-1,5-bisphosphate carboxylase/oxygenase large subunit (rbcL) gene for Trifolium alexandrinum Helaly genotype and ribulose-1,5-bisphosphate carboxylase/oxygenase large subunit (rbcL) reference gene. Thus, $95.92 \%$ of genetic similarity was recorded (fig.6).

In the light of rbcl marker identification gene, comparing cytochrome $\mathrm{c}$ oxidase subunit 1 gene (Cox 1$)$ marker gene for Trifolium alexandrinum indicate identification as Trifolium alexandrinum voucher K016Hv cytochrome c oxidase (COI) gene, partial cds; mitochondrial (Sequence ID: KU234213.1) with $100 \%$ of genetic similarity (figure 7).

Preserve the originality was detected (fig.8) through comparing cytochrome $\mathrm{c}$ oxidase (COI) gene, partial cds; mitochondrial sequence with cytochrome c oxidase (COI) gene, partial cds; mitochondrial reference sequence and showed completely identical similarity with $100 \%$ of genetic similarity.

It is important to note that DNA-based identification in Trifolium would be much more challenging without the availability of a comprehensive global monograph and biological information for most of the genus (Gillett and Taylor, 2001). Such a robust taxonomic foundation is lacking for the great majority of the world's species

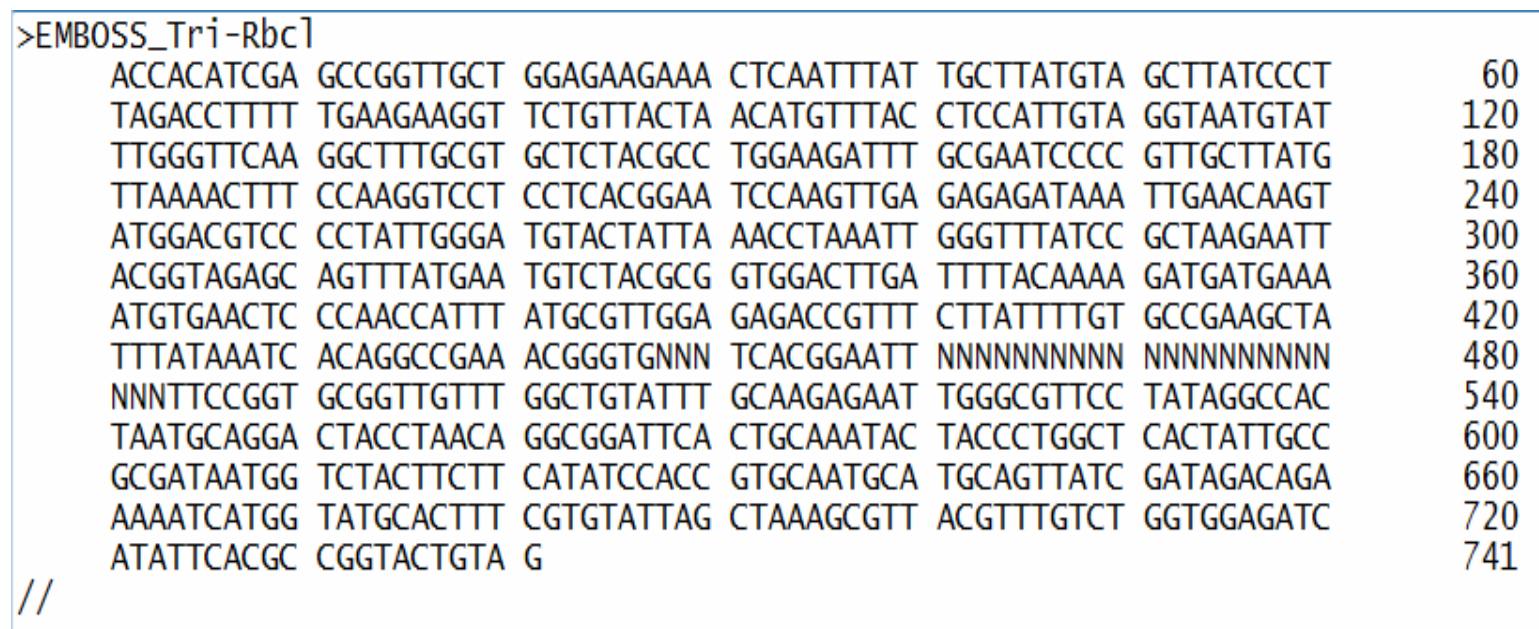

Figure 5. Ribulose-1,5-bisphosphate carboxylase/oxygenase large subunit (rbcL) marker gene sequence for Trifolium alexandrinum Helaly Genotype

(DNA Barcoding of Egyptian clover Helaly Genotype (rbcL) gene) 


\begin{tabular}{|c|c|}
\hline HM85e497.1 & CCAGTCTTGATCGTTATAAAGGACGCTGCTACCACATCGAGCCGGTTGCTGGAGAAGAAA \\
\hline EMBOSS_Tri-rbcl & СTСАATTTATTGCTTATGTAGCTTATCCCTTAGACCTTTTTGAAGAAGGTTCTGTTACTA \\
\hline HM85e4ब̄7.1 & CTCAATTTATTGCTTATGTAGCTTATCCCTTAGACCTTTTTGAGGAAGGTTCTGTTACTA \\
\hline EMBOSS_Tri-rbcl & ACATGTTTACCTCCATTGTAGGTAATGTATTTGGGTTCAAGGCTTTGCGTGCTCTACGCC \\
\hline HM85e4ब̄7.1 & ACATGTTTACCTCCATTGTAGGTAATGTATTTGGGTTCAAGGCTTTGCGTGCTCTACGCC \\
\hline EMBOSS_Tri-rbcl & TGGAAGATTTGCGAATCCCCGTTGCTTATGTTAAAACTTTCCAAGGTCCTCCTCACGGAA \\
\hline HM85e40̄7.1 & TGGAAGATTTGCGAATCCCCGTTGCTTATGTTAAAACT TTCCAAGGTCCTCCTCACGGAA \\
\hline EMBOSS_Tri-rbcl & TCCAAGTTGAGAGAGATAAATTGAACAAGTATGGACGTCCCCTATTGGGATGTACTATTA \\
\hline HM85e49̄7.1 & TCCAAGTTGAGAGAGATAAATTGAACAAGTATGGACGTCCCCTATTGGGATGTACTATTA \\
\hline EMBOSS_Tri-rbcl & AACCTAAATTGGGTTTATCCGCTAAGAATTACGGTAGAGCAGTTTATGAATGTCTACGCG \\
\hline HМ85e4ब̄7.1 & AACCTAAATTGGGTTTATCCGCTAAGAATTACGGTAGAGCAGTTTATGAATGTCTACGCG \\
\hline EMBOSS_Tri-rbcl & GTGGACTTGATTTTACAAAAGATGATGAAAATGTGAACTCCCAACCATTTATGCGTTGGA \\
\hline HM85e49̄7.1 & GTGGACTTGATTTTACAAAAGATGATGAAAATGTGAACTCCCAACCATTTATGCGTTGGA \\
\hline EMBOSS_Tri-rbcl & GAGACCGTTTCTTATTTTGTGCCGAAGCTATTTATAAATCACAGGCCGAAACGGGT GNNN \\
\hline HM85e4ब̄7.1 & GAGACCGTTTCTTATTTTGTGCCGAAGCTATTTATAAATCACAGGCCGAAACGGGTGNNN \\
\hline EMBOSS_Tri-rbcl & 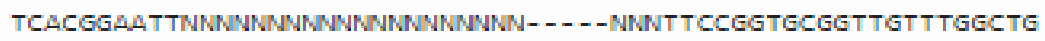 \\
\hline HМ $8584 \bar{\theta} 7.1$ & 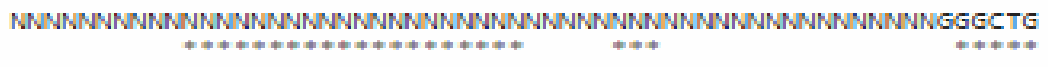 \\
\hline EMBOSS_Tri-rbc1 & TATTTGCAAGAGAATTGGGCGTTCCTATAGGCCACTAATGCAGGACTACCTAACAGGCGG \\
\hline HM85e4ब̄7.1 & TATTTGCAAGAGAATTGGGCGTTCCT - ..- ATAGTAATGCAGGACTACCTAACAGGCGG \\
\hline EMBOSS_Tri-rbcl & ATTCACTGCAAATACTACCCTGGCTCACTATTGCCGCGATAATGGTCTACTTCTTCATAT \\
\hline HM85e497.1 & ATTCACTGCAAATACTACCCTGGCTCACTATTGCCGCGATAATGGTCTACTTCTTCATAT \\
\hline EMBOSS_Tri-rbcl & CCACCGTGCAATGCATGCAGTTATCGATAGACAGAAAAATCATGGTATGCACTTTCGTGT \\
\hline HM85e49̄7.1 & CCACCGTGCAATGCATGCAGTTATCGATAGACAGAAAAATCATGGTATGCACTTTCGTGT \\
\hline EMBOSS_Tri-rbcl & ATTAGCTAAAGCGTTACGTTTGTCTGGTGGAGATCATATTCACGCCGGTACTGTAG - . - - \\
\hline HM85e40̄7.1 & ATTAGCTAAAGCGTTACGTTTGTCTGGTGGAGATCATATTCACGCCGGTACTGTAGTAGG \\
\hline $\begin{array}{l}\text { EMBOSS_Tri-rbc1 } \\
\text { HM85e4बे.1 }\end{array}$ & TAAACTTGAAGGAGAAAGGGAGATAACTTTAGGTTTTGTTGACTTACTACGTGATGATTA \\
\hline EMBOSS_Tri-rbcl & 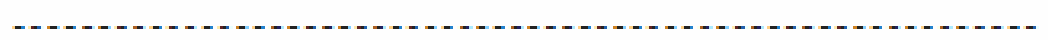 \\
\hline HM85e497.1 & TGTTGAAAAAGATAGAAGTCGCGGTATTTTTTTCACTCAGGATTGGGTTTCTTTACCGGG \\
\hline EMBOSS_Tri-rbcl & 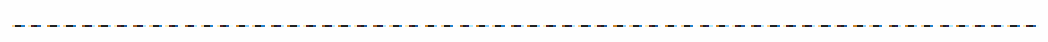 \\
\hline HM85e49̄7. & TGTTCTGCCTGTTGCTTCAGGGGGTATCCACGTTTGGCATATGCCCGCTCTGACCGAGAT \\
\hline EMBOSS_Tri-rbcl & 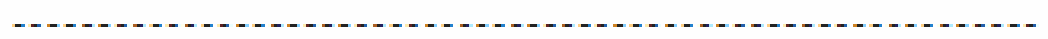 \\
\hline HM85e4ब̄ 7.1 & TTTTGGAGATGATTCTGTACTTCAATTCGGCGGAGGAACTGTAGGACACCCTTGGGGAAA \\
\hline EMBOSS_Tri-rbcl & $\ldots-.$. \\
\hline $\mathrm{H} M 8584 \overline{9} 7.1$ & TGCAC \\
\hline
\end{tabular}

Figure 6. Comparison alignments between rbcl marker gene for Trifolium alexandrinum Helaly genotype and rbcl reference sequence 
PEMBOSS_Tri-COX

$\begin{array}{lr}\text { TCTTTCAGCT AATATTGCCC ATAGAGGCCC TTCTGTTGAT TTAGCTATTT TTAGATTACA } & 60 \\ \text { TTTAGCTGGT GTATCATCAA TTTAGGAGC AATTAATTT ATTACTACCA TGATTAATAT } & 120 \\ \text { ACGACCTATT GGTATACAAT TAGATAAACT TCCTTTATTT GCTTGGTCAG TTTTAATTAC } & 180 \\ \text { TGCTATTTTA CTTCTGCTTT CCCTCCCTGT ATTAGCAGGA GCAATCACTA TGCTTTTAAC } & 240 \\ \text { AGATCGAAAT ATTAATACTT CATTTTTTGA CCCTGCAGGA GGTGGGGA } & 289\end{array}$

Figure 7. Cytochrome c oxidase subunit 1 gene (Cox1) marker gene sequence for Trifolium alexandrinum Helaly genotype

\author{
(DNA Barcoding of Egyptian clover Helaly Genotype (Cox 1) gene)
}

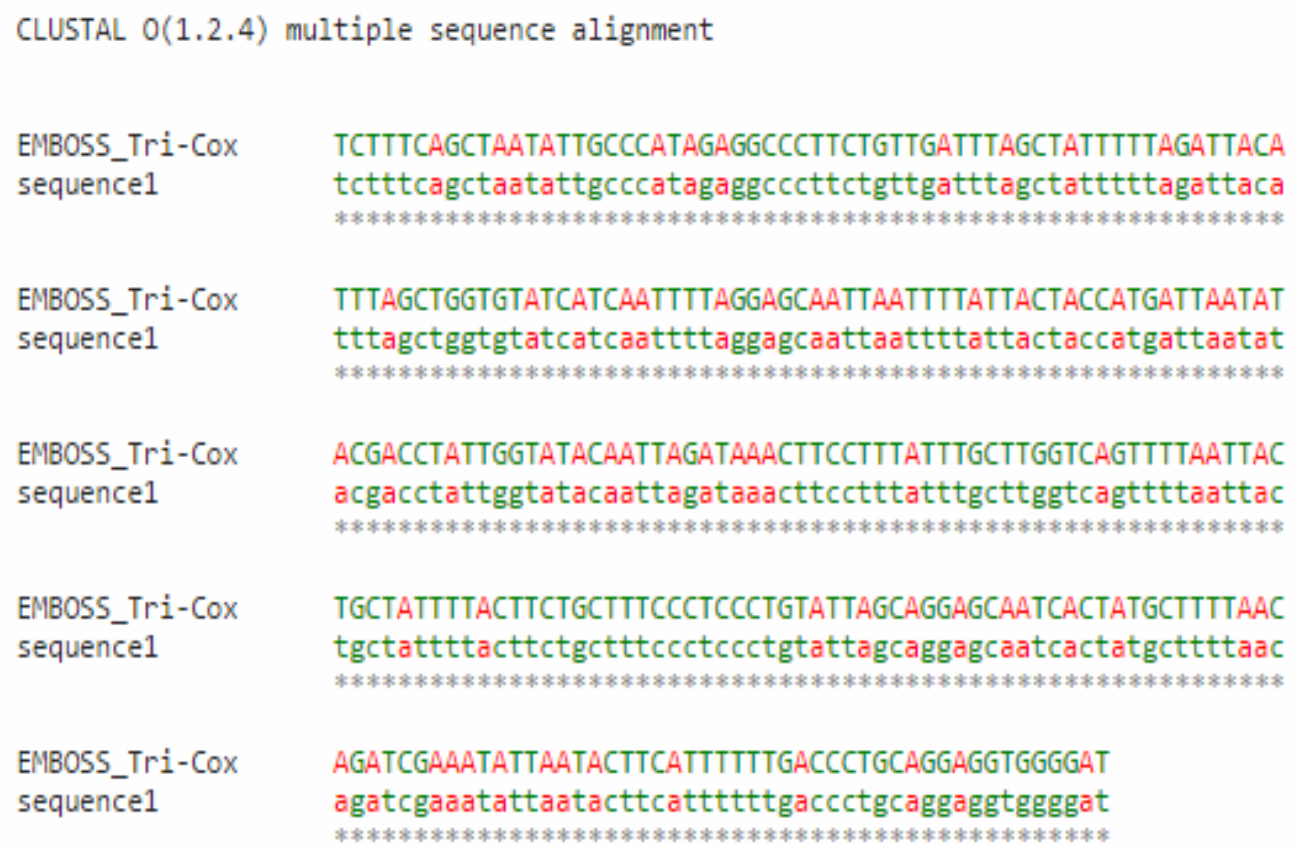

Figure 8. Comparison alignments between cytochrome c oxidase subunit 1 gene for Trifolium alexandrinum Helaly genotype and rbcl reference sequence

The results obtained for identification and evaluation of Similarity with the original genetic base are in agreements with the results of Ganopoulos et al., (2012). They applied Barcode-DNA High-Resolution Melting (Bar-HRM) analysis method using the universal nuclear plant DNA barcoding region ITS2 for the identification, adulteration and quantification of the main pasture species. Bar-HRM detected Medicago lupulina adulterants in Trifolium pratense seeds as low as 1:100. In conclusion, Bar-HRM analysis could be a faster with higher resolution and cost-effective alternative method to authenticate forage and pasture species and quantitatively detect the purity of their seeds or their feed products. More light was added to our findings Gillett and Taylor, (2001). They applied
DNA-based identification in Trifolium would be much more challenging without the availability of a comprehensive global monograph (Zohary and Heller, 1984) and biological information for most of the genus. Such a robust taxonomic foundation is lacking for the great majority of the world's specie

Effectiveness of several genes (cox1, rbcL, 18S and ITS rDNA) were assessed to distinguish cryptic species within the model morphospecies Coxl divergence was usually much greater than $\mathrm{rbcL}$ divergence and always much more variable than $18 \mathrm{~S}$ rDNA. ITS rDNA sequences were more variable than cox1, but wellknown problems concerning intragenomic variability caution against its use in identification. More information and less sequencing effort mean that cox1 
can be a very useful aid in diatom identification. The usefulness of cox1 for determining phylogenetic relationships among tree topologies were very similar, although support values were generally lower for cox 1 (Evans et al., 2007). With agreements to our findings, Hawkins et al., (2015) DNA metabarcoding and melissopalynology were able to detect the most abundant floral components of honey and plant Taxt. There was $92 \%$ correspondence for the plant taxa that had an abundance of over $20 \%$. However, the level of similarity when all taxa were compared was lower, ranging from 22-45, and there was little correspondence between the relative abundance of taxa found using the two techniques. DNA metabarcoding provided much greater repreatability, with a $64 \%$ taxa match compared to $28 \%$ with melisspalynology.

Altschul et al., (1990) introduced BLAST tool for finding sequence similarity (Basic Local Alignment Tool). BLAST approximates alignments that optimize a measure of local similarity, the Maximal segment pair score. Such an alignment may be thought of as minimizing the evolutionary distance or maximizing the similarity between two sequences compared. BLAST employs a measure based on well - defined mutation scores to compare two sequences, whether DNA or amino acid sequences to discover sequence homology. Pairwise alignment is deciding if a pair of sequences is evolutionary related or not. Pairwise similarity scores for the sequences that be fed into a cluster analysis or tree calculating program. The tree is calculated to place more similar paris of sequences closer together on the tree than sequences that are less similar.

\section{CONCLUSION}

This work aims at evaluating and identifying Medicago sativa and Trifolium alexandrinum (two important Forage crops) for breeding programs susceptibility via two bar-coding genes ( $\mathrm{rbcl}$ and Cox1 genes).

Identification of Medicago sativa Baladi 1 genotype was performed through rbcl and Cox1 genes identified as Medicago sativa voucher G00199095 ribulose-1,5bisphosphate carboxylase/oxygenase large subunit (rbcL) gene, partial cds; chloroplast (Sequence ID: KJ204375.1) and Medicago sativa voucher Ahrendsen_23 for $\mathrm{rbcl}$ and Cox1 genes respectively. Moreover, Trifolium alexandrinum Helaly genotype identified as Trifolium alexandrinum (Sequence ID: HM850407.1) and Trifolium alexandrinum voucher K-016Hv (Sequence ID: KU234213.1) as rbcl and Cox1 genes respectively. Trifolium alexandrinum showed more success for breeding program comparing with Medicago sativa as a result of genetic similarity superiority with origin sequences.

\section{REFERENCES}

Aldrich J, B. Cherne, E. Merlin and J. Palmer 1987. Sequence of the $r b c \mathrm{~L}$ gene for the large subunit of ribulose bisphosphate carboxylase-oxygenase from alfalfa. Nucleic Acids Res (1987) 15 (2): 868.

Altshcul, S.F., W. Gish., W.Miller., E.W.Myers and D. Lipman 1990. "Basic Local Alignment Search Tool", Journal of Molecular Biology, Vol. 215 : PP.403-410.

Badr$$
\text { A, }
$$

$\mathrm{H}$.

ElShazlyhttp://www.sciencedirect.com/science/article/pii/S1 687157X11000254 - aff2 2001. Molecular approaches to origin, ancestry and domestication history of crop plants: Barley and clover as examples. Journal of Genetic Engineering and Biotechnology. Volume 10, Issue 1, June 2012, Pages 1-12.

Blaxter, M.L.,(2004. The promise of a DNA taxonomy. Philos. Trans. R. Soc. Lond. Biol. Sci. 359, 669-679.

Ellison N, W. A., A.B. Liston, J.C. Steiner, W. Williams, N.L. Taylor 2006. Molecular phylogenetics of the clover genus (Trifolium-Leguminosae), Molecular Phylogenetics and Evolution 39 (2006) 688-705.

Evans M; Wortley AH., Mann DG. 2007. An Assessment of Potential diatom "Barcode" genes (cox1, rbcL, 185 and ITS rDNA) and their effectiveness in determining Relationships in Taxa Protist 2007 Jul: 158(3): $344-364$. Erup 207, Jun 19.

Gael J. A. Kergoat, Alex Delobel,b and Jean-Francois Silvaina 2004. Phylogeny and host-specificity of European seed beetles (Coleoptera, Bruchidae), new insights from molecular and ecological data. Molecular Phylogenetics and Evolution 32 (2004) 855-865.

Ganopoulos I., P. Madesis and A. Tsaftaris 2012. Universal ITS2 Barcoding DNA Region Coupled with HighResolution Melting (HRM) Analysis for Seed Authentication and Adulteration Testing in Leguminous Forage and Pasture Species. Plant Molecular Biology Reporter. December 2012, Volume 30, Issue 6, pp 1322-1328.

Gillett JM, NL. Taylor 2001. The world of clovers. Ames, IA, Iowa State University Press. $457 \mathrm{p}$

Gurdon C and P. Maliga 2014. Two distinct plastid genome configurations and unprecedented intraspecies length variation in the accD coding region in Medicago truncatula. DNA Res. 2014 Aug;21(4):417-27. doi: 10.1093/dnares/dsu007. Epub 2014 Mar 17.

Hawkins, J., Devere, N. Griffith, A. Ford, C. Allain guillaume, J. Hegarty, M. Baillic, L. and Adams Groomy B. 2015. Using DNA metabarcoding to Identify the Floral Composition of Plant Taxa and Honey. A new Tool for Investigating plant and Honey bee. Forraging Preferences - Plos ONE, 10(8). E0134735.Iss N. 1932 6203 Available from : http://eprints.uwe.ac.uk/25992.

Kress, W.J., K.J. Wurdack, E.A. Zimmer, L.A. Weigt, D.H. Janzen 2005. Use of DNA barcodes to identify Xowering plants. Proc. Natl. Acad. Sci. USA 102, 8369-8374. 
Lavin, M., J.J. Doyle, J.D. Palmer 1990. Evolutionary signiWcance of the loss of the chloroplast-DNA inverted repeat in the Leguminosae subfamily Papilionoideae. Evolution 44, 390-402.

Liston, A., 1995. Use of the polymerase chain reaction to survey for the loss of the inverted repeat in the legume chloroplast genome. In: Crisp, M.D., Doyle, J.J. (Eds.), Advances in Legume Systematics, Part 7. Royal Botanic Gardens, Kew, UK, pp. 31-40.

Madesis1 P. I., P. Ralli Ganopoulos and A. Tsaftaris 2012. Barcoding the major Mediterranean leguminous crops by combining universal chloroplast and nuclear DNA sequence targets. Genet. Mol. Res. 11 (3): 2548-2558 (2012).

Morris, J.B., S.L. Greene 2001. DeWning a multiple-use germplasm collection for the genus Trifolium. Crop Sci. 41, 893-901.
Newmaster S. G., Emailauthor, Grguric M. Shanmug Hanandh and S. Ramalingam and S. Ragupathy 2013. DNA barcoding detects contamination and substitution in North American herbal products. BMC Medicine201311:222. DOI: 10.1186/1741-7015-11-222.

Sharawy S and E. Karakishi 2015. Taxonomic Relationships of Some Species of Orobanche 1. Evidence from Rapd-pcr and Issr Markers. Pak. J. Bot., 47(2): 437-452, 2015.

Tautz, D., P. Arctander, A. Minelli, R.H. Thomas, A.P. Vogler 2003. A plea for DNA taxonomy. Trends Ecol. Evol. 18, 70-74.

Young ND, F. Debellé, G. Oldroyd, R. Geurts, S.B. Cannon, M.K. Udvardi, V.A. Benedito, K. Mayer, J. Gouzy, H. Schoof 2011. The Medicago genome provides insight into the evolution of rhizobial symbioses. Nature 480: 520 524.

Zohary, M., D. Heller 1984. The Genus Trifolium. Israel Academy of Sciences and Humanities, Jerusalem, Israel.

\section{الملذص العري

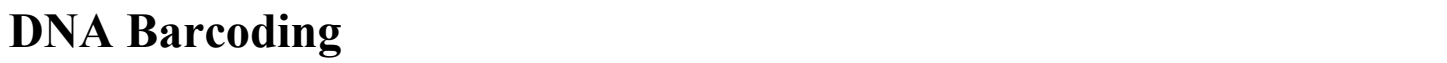 \\ عبد العزيزطلهت بندق}

(204375.1 أما بالنسبة للبوسيم المسقاوي صف الهلالي فقد

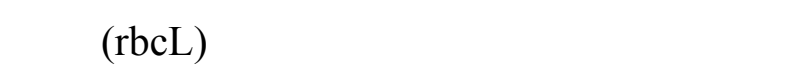

Trifolum Alexandrinum (Sequence ID : HM850407.1)

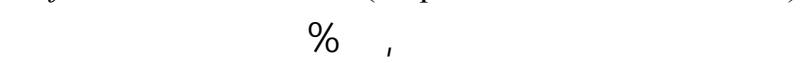

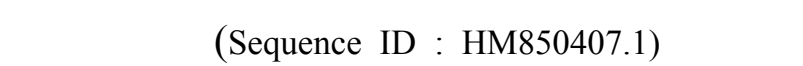

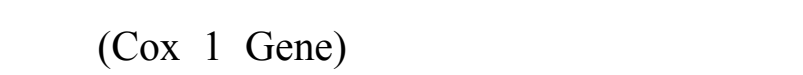
Trifolum alexandrinum voucher K-016 HV (Sequence وأعطى نسبة تشابه · : KU234213.1) بالأصل ال -وراثي (Sequence ID : HM850407.1) وف مي ضوء النتائج المتحصل عليها مت لستخدلم التشابه الوراثي مع : الأمع

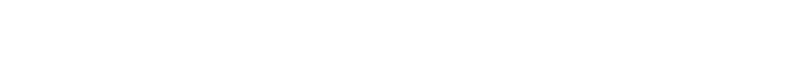

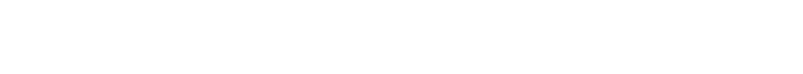

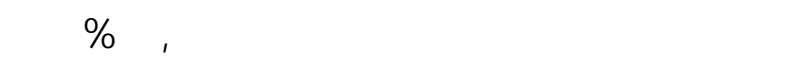
الأصل الوراثي بالمقارينة بالبرسيم الحجازي بلدي الدية ا الـ ذي بلغت نسبة ظابقه مع الأصل الوراثي 7, - 9\% .
في هذه الدرلسة مُ عملشفرة كودية مميزة لك للاًم نن

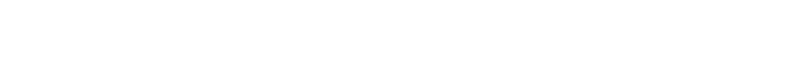

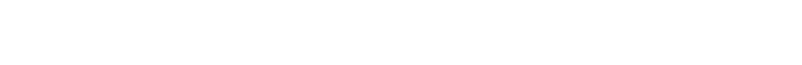
صف الهلالي والبوسيم الحجازي صف بلدي ا لب ـرامج

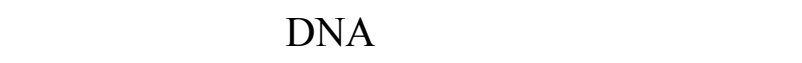

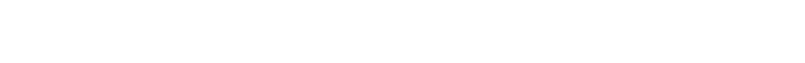
وهما .rbcl and Cox1 genes). ولقد أظهرت النتائج أن

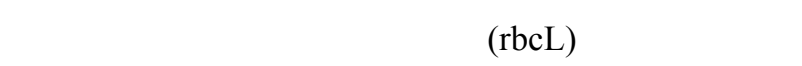

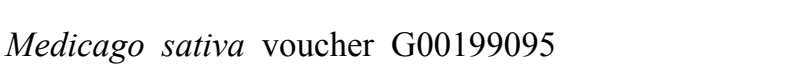
ribulose -1,5- bisphosphate carboxylase /oxygenase

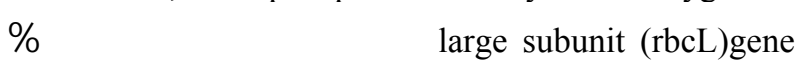

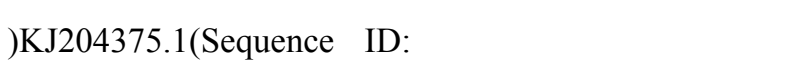

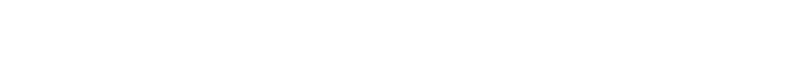

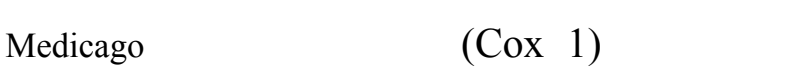
Sativa Voucher Ahrendsen-23 وأعطى نسبة تشابه بلغت

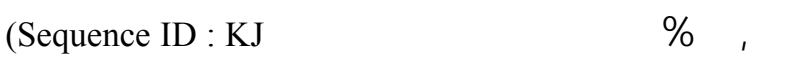

